\title{
A diversidade de interpretações como fator constituinte da formação docente: leitura e observação*
}

\section{The interpretations diversity as a teacher education constituting factor: reading and observation}

\author{
Maria José P. M. de Almeida** \\ Roberto Nardi*** \\ Fernanda Cátia Bozelli****
}

\begin{abstract}
RESUMO
Neste artigo apresentamos a análise de interpretações de estudantes em trabalhos desenvolvidos em duas disciplinas de cursos de Licenciatura em Física, nas quais realizamos atividades bastante distintas, uma envolvendo a leitura e outra a observação pelos licenciandos. Buscamos compreender falas escritas pelos estudantes como parte dessas atividades, e procuramos evidenciar a diversidade de interpretações e a relevância desse trabalho para a formação inicial. O apoio teórico em que nos sustentamos foi a análise de discurso na vertente originada na França por Michel Pêcheux. A consideração da não transparência da linguagem, e as noções de condições de produção, memória discursiva e repetição, bem como alguns aportes sobre possíveis papéis da observação na construção científica, contribuíram para a compreensão de discursos escritos pelos estudantes. Mostramos a diversidade de interpretações dos licenciados: ao opinarem sobre a possi-
\end{abstract}

* Apoio CNPq e FAPESP.

** Professora Titular do Departamento de Ensino e Práticas Culturais e coordenadora do grupo de estudo e pesquisa em Ciência e Ensino - gepCE, Faculdade de Educação, Universidade Estadual de Campinas (UNICAMP). Campinas-SP. E-mail: mjpma@unicamp.br

*** Professor Adjunto, livre docente do Departamento de Educação e coordenador do grupo de Pesquisa em Ensino de Ciências, Faculdade de Ciências, Universidade Estadual Paulista (UNESP). Bauru-SP. E-mail: nardi@fc.unesp.br

**** Doutoranda do Programa de Pós-Graduação em Educação para a Ciência, Faculdade de Ciências, Universidade Estadual Paulista (UNESP). Bauru-SP. E-mail: ferboz@fc.unesp.br 
bilidade ou não de se trabalhar a física moderna e contemporânea no ensino médio, depois de lerem um texto envolvendo esse tema, e ao redigirem um texto sobre a observação na pesquisa científica.

Palavras-chave: leitura; observação; interpretação; formação inicial; análise do discurso.

\begin{abstract}
In this paper we present an analysis of students' interpretations about tasks assigned during two courses taught in undergraduate physics preservice programs, in which we carried out among future physics teachers well distinct activities, one involving reading and another observation. We looked for comprehending their written speech as part of these activities, and to show the diversity of interpretations and the relevance of this task for teachers' initial training. The theoretical support of this study was the discourse analysis approach initiated in France by Michel Pêcheux. The no language transparency consideration and the production conditions, discursive memory and repetition notions, as well as some possible role played by observation in the scientific construction approaches, contributed to comprehend the students' written discourses. We showed the future teachers interpretations diversity: when thinking about the possibility to teach or not modern physics in high school level, after reading a text about this subject; and when writing a text about the role of observation in the scientific research.

Keywords: reading; observation; interpretation; teacher undergraduate education; discourse analysis.
\end{abstract}

\title{
Origens do estudo e apoio teórico metodológico
}

Este artigo tem sua origem no desenvolvimento de um projeto ${ }^{1}$ de pesquisa no qual um dos objetivos foi estabelecer relações entre a manutenção e/ou modificação de mediações de ensino projetadas e conduzidas pelos pesquisadores que participaram do projeto e as elaborações de estudantes universitários, seus alunos em disciplinas do ensino superior.

Aqui, apresentamos a análise de aspectos comuns ao trabalho desenvolvido em duas disciplinas de cursos de Licenciatura em Física, nas quais realizamos

1. Produção do ensino, saberes cotidianos e científicos no imaginário de estudantes universitários, coordenado pela Prof ${ }^{a}$. Roseli Cação, desenvolvido na UNICAMP e apoiado pelo CNPq. 
atividades bastante distintas, uma envolvendo a leitura e outra a observação pelos licenciandos. Buscamos compreender falas escritas pelos estudantes como parte dessas atividades, e procuramos evidenciar a diversidade de interpretações e a relevância do trabalho com as interpretações dos licenciandos na sua formação inicial.

A constituição dos dados que permitiram analisar a diversidade de interpretações dos licenciandos é enfocada a partir de uma avaliação de leitura realizada na Universidade Estadual de Campinas e a partir de uma atividade de observação, desenvolvida na Universidade Estadual Paulista, campus de Bauru. O principal aporte teórico que permitiu nossa compreensão dos aspectos aqui apresentados foi a análise do discurso na vertente iniciada na França por Michel Pêcheux. Apoiamo-nos principalmente em trabalhos desenvolvidos no Brasil por Eni Orlandi. Esse aporte, relacionado às preocupações com a linguagem, situa este trabalho entre aqueles que na Educação em Ciências têm já de há longo tempo pensado questões de linguagem nessa área de pesquisa, incluindo vários estudos nos grupos de pesquisa a que pertencem os autores deste artigo.

Da vertente da análise do discurso em que nos apoiamos, sintetizamos aqui as principais noções que contribuíram tanto para a reflexão sobre pressupostos subjacentes às atividades propostas, quanto para a seleção e análise das interpretações dos estudantes, pois:

[...] o suporte teórico não entra em cena apenas na análise de informações obtidas com a intenção de solucionar um problema; as convicções que esse referencial possibilita, direta ou indiretamente, já se fazem presentes na definição desse problema. Por outro lado a construção de um dispositivo analítico vai além do simples uso do referencial teórico, e está associado à natureza do problema a ser analisado (ALMEIDA, 2004, p. 44).

Prioritariamente assinalamos as considerações de que a linguagem não é transparente e de que as falas escritas dos estudantes são aqui assumidas como efeitos de sentidos entre locutores, ou seja, são pensadas como discursos; sendo que qualquer discurso é produzido em condições de produção específicas, tanto imediatas como não imediatas, incluindo a própria história de vida do sujeito falante.

Quanto à interpretação, ou produção de sentidos, esta obedece a condições específicas de produção, que aparecem como se fossem naturais. Ou seja, o sujeito quando fala está interpretando, atribuindo sentido às suas palavras em condições específicas, e ele o faz como se os sentidos estivessem nas palavras, 
desaparecendo suas condições de produção. Assim, parece-lhe haver transparência na interpretação. Entretanto, esta não é mero gesto de decodificação e de apreensão de sentidos. Mas também não é livre de determinações. Ela obedece à memória, o que pode dar-se com a memória institucionalizada, ou seja, o trabalho social da interpretação, o arquivo, ou com a memória constitutiva, o interdiscurso ou memória discursiva. Segundo Orlandi (1996), o autor de um discurso responde pelo que diz ou escreve, pois é suposto estar na origem desse discurso. Ou seja, o sujeito só se faz autor se o que produz for interpretável. Ele historiciza seu dizer e o que só repete (exercício mnemônico) não o faz. O que leva a autora a distinguir três tipos de repetição: a repetição empírica, ou exercício mnemônico; a formal, ou técnica de produzir frases e a histórica, que efetivamente faz a língua significar (ORLANDI, 1996).

\section{Interpretações associadas à leitura}

Para a leitura, numa perspectiva discursiva, entre os fatos que se impõem, destacamos o de que a leitura, tanto quanto a escrita, faz parte do processo de instauração do(s) sentido(s); o de que o sujeito-leitor tem suas especificidades e sua história e tanto o sujeito quanto os sentidos são determinados histórica e ideologicamente, do que decorre o fato de que há múltiplos e variados modos de leitura (ORLANDI, 1988).

Neste estudo analisamos discursos que foram obtidos junto a licenciandos que estavam cursando a disciplina Didática para o Ensino de Física na Universidade Estadual de Campinas. Entre os objetivos da disciplina nesse semestre, destacamos o propósito de contribuir para que os licenciandos analisassem criticamente e se posicionassem quanto às suas representações sobre ciência e ensino, e especialmente sobre o ensino da Física no grau médio. Já entre as estratégias e recursos didáticos colocados em funcionamento tendo em vista alcançar os objetivos da disciplina, foi proposta a leitura e discussão de parte das jornadas temáticas idealizadas e dirigidas por Morin (2002). Jornadas que, segundo seu dirigente, foram realizadas em resposta a um convite do então Ministro da Educação da França para que presidisse um conselho científico destinado a fazer sugestões para o ensino médio. Da parte das jornadas intitulada $O$ Mundo (MORIN, 2002, p. 27-72) constam seis textos curtos elaborados por físicos, por cosmólogos e por um membro de academia de ciências. A leitura desses textos foi proposta aos licenciandos para ser realizada extraclasse, tendo havido posteriormente uma discussão com toda a turma em aula, na qual essencialmente 
se procurou resolver as dúvidas e debater aquilo que havia chamado a atenção dos estudantes. Estes também foram informados da possibilidade de inclusão dos textos em avaliação escrita que seria realizada em seguida. A intenção, no entanto, não era obter uma possível resposta considerada como certa, mas sim criar condições de produção adequadas à manifestação das posições/opiniões dos estudantes visando seu debate e oportunizando a reflexão sobre essas posições/ opiniões. Outra finalidade da avaliação era aumentar a probabilidade da leitura, além de se visar a partir da compreensão das interpretações dos estudantes replanejar leituras futuras, bem como outros tipos de atividades na disciplina.

As interpretações que aqui destacamos foram obtidas como resposta à seguinte questão formulada numa avaliação escrita e respondida individualmente sem consulta aos textos:

Pensando na possibilidade de que o ensino seja realizado tendo em vista a formação profissional ou a formação cultural do indivíduo, conforme texto lido nesta disciplina, comente a possibilidade de se trabalhar a Física Moderna no Ensino Médio.

Dos textos das jornadas, que foram propostos aos licenciandos para leitura, o único que se referia à formação profissional e cultural era o de Lévy-Leblond (2002). E, além disso, o título desse texto, "É possível ensinar a física moderna?", estava estritamente relacionado à questão formulada. A posição do autor nesse texto é a de que os saberes técnicos devem ser adquiridos mais tarde em formações especializadas, enquanto que o ensino médio se destinaria à formação cultural e cidadã. A concordância com essa função para o ensino médio havia contribuído para que incluíssemos esse texto no plano de curso da disciplina. Entretanto, considerávamos que o conhecimento de alguns aspectos da física moderna é parte integrante da formação cultural e cidadã nos dias de hoje.

Quanto ao foco principal, explicitado no título do artigo, a possibilidade de introdução da física moderna no ensino médio, o autor, referindo-se especificamente à mecânica quântica evidencia as transformações profundas que seus conceitos provocaram na ciência e suas realizações na técnica, além de apontar o funcionamento da microfísica em nossa escola, exemplificando com o laser num leitor de CD. Entretanto, por outro lado, manifesta seu ceticismo em relação à possibilidade de ensinar esse conteúdo para grande número de pessoas e também questiona a necessidade desse ensino. Lévy-Léblond (2002) chega inclusive a dizer, referindo-se à tecnologia, que esta funciona como uma caixa preta, ou seja, um sistema do qual não se conhece o funcionamento interno, mas 
apenas as características de entrada e saída.

No entanto, logo a seguir, o autor ressalta que, em se tratando "[...] de saberes que têm um alcance cultural, certos conhecimentos da cosmologia ou da quântica têm uma verdadeira vocação para modificar nossas representações do mundo" (LEVY-LÉBLOND, 2002, p. 70). Concepção esta que sem dúvida precisa ser devidamente discutida e aprofundada na formação profissional do futuro professor de física. Mas, Lévy-Léblond (2002) coloca em dúvida a possibilidade dos produtores e detentores desses saberes os compartilharem com outras pessoas. E, explicita sua posição ao dizer que:

[...] para que um saber científico possa mostrar sua plena dimensão cultural, é preciso que ele esteja intimamente ligado ao conjunto do corpo de conhecimentos e, antes de mais nada, ao saber comum (que na maioria dos casos é transmitido em outro lugar que a escola - pela família ou mesmo pela mídia). É preciso, além do mais, que este saber seja recolocado em seu contexto histórico e filosófico, o que significa dizer que esta questão escapa aos pesquisadores de uma dada disciplina científica (LÉVYLÉBLOND, 2002, p. 70).

Mesmo com essa pequena síntese podemos notar o caráter abrangente e a diversidade de ideias contidas no texto e, buscando compreender as interpretações coletadas, apontamos a diversidade dessas interpretações e evidenciamos a importância de debatê-las tendo em vista futuras posições que o docente deverá assumir.

Dos 16 licenciandos que responderam a questão, um deles $(6,2 \%)$ apresentou vantagens e desvantagens ao comentar a possibilidade de trabalhar física moderna no ensino médio e disse em que situação e de que maneira seria conveniente esse trabalho; três $(18,7 \%)$ negaram essa possibilidade e 12 $(75,0 \%)$ apresentaram argumentos favoráveis ao trabalho com física moderna e contemporânea no ensino médio. Por outro lado, entre os 16 , em apenas três não pudemos encontrar um forte indício de leitura do texto ou participação na sua discussão. Consideramos um dos indícios fortes da leitura os estudantes terem se referido, nas suas justificativas para se ensinar física moderna e contemporânea no ensino médio, a uma das duas possibilidades citadas por Lévy-Léblond como justificativa para se ensinar física: visar com o ensino a formação cultural ou a formação profissional.

É interessante notar que, embora pelas suas argumentações, se possa supor que ao redigir e falar de profissionalização o autor do texto tenha se referido à formação do cientista, por pelo menos um dos licenciandos a profissionalização 
foi pensada como sendo a que ocorre no ensino médio:

\begin{abstract}
- A Física moderna pode ser trabalhada no Ensino Médio qualquer que seja o seu objetivo: a formação cultural ou profissional, bastando apenas adaptar o enfoque dado a este conteúdo. Em um Ensino Médio "profissionalizante" seria importante ressaltar a influência deste conhecimento nas aplicações práticas, como a física quântica na eletrônica ou a relatividade nas comunicações via satélite. Já em um "ensino cultural” se evidenciaria o processo de produção destes conhecimentos: que raciocínios e reflexões foram feitas diante dos problemas que levaram ao desenvolvimento destes conhecimentos.
\end{abstract}

Cabe aqui ressaltar que, a questão, como foi formulada, constituiu-se em uma condição de produção imediata. Esta possibilitou à maioria dos licenciandos evidenciarem a leitura/participação na discussão do texto em questão, mas também manifestarem suas reflexões a partir da memória de outras leituras, de outros textos das jornadas ou mesmo de textos diferentes dos trabalhados em aula. Essa questão não foi apenas mais uma questão numa avaliação escrita, entre aquelas destinadas à cobrança de uma leitura parafrástica de um texto. Nos discursos dos licenciandos notamos principalmente a repetição histórica a que nos referimos nos aportes teóricos. Como nos seguintes exemplos:

\footnotetext{
Vantagens:

- curiosidade natural e entusiasmo dos alunos;

- necessidade dos alunos se posicionarem de forma consciente, enquanto seres-humanos, em relação a avanços da física (e de qualquer outra ciência) que podem interferir diretamente em suas vidas.

- [...] só seria coerente introduzir física moderna no ensino médio tendo em vista a formação cultural e, nesse caso, seria necessário simplificar as teorias envolvidas até o nível em que os alunos possam compreender as idéias gerais com o mínimo de possibilidade de equívocos. Tomando-se esses cuidados, o ensino de física moderna seria bem recebido pelos alunos do ensino médio, mas também estaria desempenhando um importante papel na formação cultural (e crítica) dos mesmos.
}

\title{
Desvantagens:
}

- impossibilidade de os alunos compreenderem plenamente o tema;

- possibilidade de associarem conceitos científicos "mal digeridos" com fantasias e mitos, construindo crenças que não correspondem à realidade. 
Por outro lado, sabemos que, no referencial teórico da análise do discurso na linha adotada, uma leitura comporta múltiplas interpretações, o que não implica em que qualquer interpretação possa ser aceita. E é interessante notar que, foi nos licenciandos que se manifestaram contra o trabalho com mecânica quântica no ensino médio que encontramos mais equívocos de interpretação do texto. Vejamos as seguintes respostas:

- Temos que antes de dar ao aluno uma formação profissional devemos dar uma formação cultural, a física quântica que é muito pouco aplicada em nível profissional, pensamos então que não seria viável ensiná-la nem em nível profissional, quanto menos na formação cultural que formaria um indivíduo com deficiência em quântica, mas sobrando caráter e cidadania.

- Segundo o último texto da 1. jornada, é necessário antes de mais nada situar o termo "moderno", e fazendo isso vemos que a chamada física moderna possui uma base epistemológica não sólida, o que torna mais importante a discussão filosófica da ciência ao invés de lecionar física moderna, no ensino médio, pois este possui uma função de formação cultural do indivíduo e não técnica. Obs.: um exemplo importante em um desses textos da $1 .^{\mathrm{a}}$ jornada é o fato que não precisamos saber como funciona um carro para saber guiá-lo.

Certamente as posições que esses dois estudantes manifestaram não podem ser atribuídas ao autor do texto. Já na fala a seguir, podemos notar a forte influência do que aqui chamamos de discurso do cotidiano, presente, entre outros textos dirigidos ao professor, nos Parâmetros Curriculares Nacionais (BRASIL, 1999), sem que, entretanto, o licenciando se dê conta do quanto atualmente o cotidiano dos estudantes de ensino médio está impregnado de dispositivos baseados na física quântica:

- Tendo em vista a formação profissional ou cultural o ensino deve estar voltado aos conhecimentos que integram o saber científico e o saber cotidiano de forma a esclarecer o indivíduo quanto aos fenômenos que o cerca e apresentar novos horizontes quanto aos fenômenos que o cerca para seu entendimento do mundo.

- Quando se fala de física Moderna estamos trabalhando conceitos que ainda não estão bem entendidos e presentes na vida cotidiana de um indivíduo, sendo este conceito desenvolvido sob uma abordagem matemática acima de tudo. Desta forma vemos que trabalhar Física Moderna no Ensino Médio se torna uma tarefa muito complicada e com pouco retorno no âmbito de 
que o estudante usará estes conceitos em sua vida cotidiana.

É interessante notar que também a física clássica é ensinada tanto no ensino médio quanto no superior quase que exclusivamente em linguagem matemática, situação que esse último estudante não menciona em sua fala.

\section{Interpretações associadas à observação}

Outra parte das interpretações analisadas neste artigo foi obtida em uma atividade desenvolvida numa das disciplinas de Metodologia e Prática de Ensino de Física na Faculdade de Ciências da Universidade Estadual Paulista, campus de Bauru. Essa atividade tinha como um de seus objetivos o debate com os estudantes do papel da observação no processo de construção da ciência e foi realizada em duas etapas.

$\mathrm{Na}$ primeira delas, o docente responsável pela disciplina solicitou aos alunos dessa turma que se agrupassem em duplas, conforme suas preferências e entregou a cada uma das duplas folhas (praticamente iguais) de uma mesma árvore solicitando-lhes que observassem e relatassem as características observadas. Em seguida, pediu para que uma pessoa de cada dupla descrevesse, por escrito, o objeto observado. Resumos das descrições de cada uma das duplas foram anotados na lousa pelo professor. Ao final das anotações foram abertas as discussões, que culminaram, de uma forma geral, com a compreensão de que um mesmo objeto, observado por diferentes observadores, é descrito de forma diferente, ou seja, são diferentes as interpretações que os estudantes fazem da tarefa a ser realizada.

Depois que todos os grupos relataram suas descrições provenientes da observação da folha, o docente fez alguns comentários, destacando a diversidade encontrada nas duplas e também sobre posições em relação à observação na pesquisa científica.

$\mathrm{Na}$ segunda etapa, na semana seguinte, o docente distribuiu uma folha a cada aluno, solicitando que eles redigissem um texto, sobre a observação na pesquisa cientifica. Antes de apresentarmos alguns exemplos de cada uma das duas fases, vamos previamente fazer alguns comentários sobre o papel da observação na pesquisa.

Autores como Hanson (1975) entendem que a ciência não se inicia com a observação, já que um tipo de teoria a precede e que as observações não se 
assentam em uma base firme para que o conhecimento científico seja construído. Ainda segundo esse autor, dois observadores não veem a mesma coisa em um mesmo conjunto de dados. Chalmers (1993) também argumenta que o que um observador vê depende de sua experiência, de seu conhecimento, de suas expectativas e de seu estado geral interior:

[...] observadores vendo a mesma cena do mesmo lugar vêem a mesma coisa, mas interpretam o que vêem diferentemente [...] Na medida em que se trata da percepção, a única coisa com a qual um observador tem contato direto e imediato, são suas experiências. Essas experiências não são dadas como únicas e imutáveis, mas variam com as experiências e conhecimento do observador (CHALMERS, 1993, p. 51-52).

No entanto, Silva (2007, p. 38-39) argumenta que "a natureza das imagens formadas na retina dos observadores está relacionada com suas culturas. Dessa forma, o que um observador vê, ou seja, a experiência visual que um observador tem ao ver um objeto é o resultado de sua experiência passada, de seu conhecimento e de suas expectativas".

Mas, para Silveira (1992, p. 36), o que prevalece no Ensino de Ciências é a concepção epistemológica conhecida como empirismo-indutivismo, na qual "a observação é a fonte e a função do conhecimento".

No sentido de ultrapassar esse tipo de posicionamento, Dourado e Sequeira (2006, p. 7) defendem a necessidade de "uma intervenção de fundo que permita a evolução das concepções indutivistas que muitos professores ainda perfilham e que os conduzem à implementação de metodologias de ensino baseadas no método científico".

Dessa forma, a atividade de observação desenvolvida com os licenciandos em física visou discutir com eles aspectos relativos ao papel da observação e suas limitações. A compreensão das interpretações transcritas a seguir evidencia a relevância da atividade realizada. Alguns exemplos de registros de observação realizados por diferentes duplas evidenciam a diversidade de fatores considerados pelos licenciandos. Apresentamos a seguir três registros:

\section{1. ${ }^{\circ}$ Registro}

- comprimento: $33,3 \mathrm{~cm}$, largura máxima: 18,5 cm;

- posição: um caule e 14 folhas;

- variação do comprimento das folhas: $6,8 \mathrm{~cm}$ a $10,2 \mathrm{~cm}$;

- cor: caule (verde-água); parte superior (verde-escuro); parte inferior 
(verde água-marinha);

- inodoro;

- distribuição geométrica: folhas começam a partir de $6,8 \mathrm{~cm}$ do caule; simetricamente distribuídas na direita e na esquerda.

\section{$2^{\cdot 0}$ Registro}

- um galho constituído de várias folhas;

- formato do galho parece uma folha;

- parte central do galho: segura todas as outras partes;

- folhas bem distribuídas; simetricamente colocadas;

- galho tem cor verde; folhas e caule verdes, mas o caule possui uma tonalidade menor de verde;

- contorno das folhas tem o formato de "serrote".

\section{$3^{.0}$ Registro}

- distribuição geral: o ramo é constituído de uma haste central: "caule". Tamanho de 21,5 cm;

- seccionado de oito partes que variam de tamanho e espessura;

- no final de cada secção sai duas folhas de cada haste, uma para cada lado;

- última folha fica localizada no final das hastes;

- as folhas (frente) estão distribuídas em pares.

Nesses três registros podemos notar a diversidade de itens descritos por cada uma das duplas. Ao decidirem o que deveriam considerar para realização da atividade solicitada pelo professor, os estudantes levaram em conta as condições de produção imediatas, a solicitação do professor, que foi por eles interpretada tendo em conta suas próprias memórias discursivas, suas histórias de vida. $\mathrm{E}$ algo de comum pode ser notado nessas histórias: todos eram estudantes de física e talvez por isso a ênfase nas formas e medidas. Mas a diversidade entre as descrições das duplas também pode ser notada: por exemplo, em duas delas as dimensões do objeto foram medidas, mas uma delas, com mais detalhes. $\mathrm{O}$ fato de a folha ser inodora, como aparece em um dos registros, foi objeto de atenção de apenas uma das duplas. Apenas esta, em todas as 20 duplas que realizaram a observação levou em consideração esse detalhe, ligado ao sentido do olfato.

De acordo com Hanson (1975), a ciência não se inicia com a observação porque existe uma teoria precedendo-a e, também, pelo fato que a observação não se assenta em uma base firme para que o conhecimento científico seja construído. Hodson (1998 apud SILVA, 2007), em levantamento crítico sob a forma como as pessoas concebem a Ciência, observou que elas entendem que a observação promove o acesso direto e seguro ao conhecimento, além de que a Ciência começaria com a observação.

Essa forma de conceber a Ciência também é discutida por Millar (1991), 
mas diferentemente daqueles autores acima citados, para ele o método científico se inicia com a observação. Essa visão de que a observação é precedente, permeia o discurso da maioria dos textos produzidos pelos estudantes, como nos exemplos a seguir, nos quais reproduzimos trechos dos textos que eles redigiram, ou seja, escreveram suas interpretações para o que lhes havia sido solicitado e que aqui procuramos compreender²:

Afinal a observação é sempre nosso primeiro contato com um acontecimento.

Temos que entender que todo processo na evolução científica depende primeiramente da observação.

[...] na ciência, antes de ser feito qualquer dedução, pressuposto ou estudo aprofundado sobre algo, é impressindivel a observação detalha do objeto, fenômeno.

[...] uma pesquisa se inicia, a partir de "observação" desses assuntos/ fatos/fenômenos.

- A observação em si é um dos principais pontos de sustentação da ciência, já que, a história nos mostra que sempre antes de uma teoria ou uma hipótese vem uma série de observações, sendo que ainda hoje é assim.

Mas outros estudantes apresentaram interpretações bastante diferentes, que levam em conta a subjetividade de quem observa, como comentado em Chalmers (1993) e Silva (2007). Entretanto, essas observações não são idênticas. Nas duas interpretações a seguir notamos o foco na influência dos conhecimentos adquiridos anteriormente por quem observa:

[...] o ato de observar depende do observador, eu como físico analizei a folha em dimensões, formatos, peso, ou seja medidas que eu estou abtuado, diferente de um biólogo, ou de um químico por exemplo, que veriam a mesma folha por outro ângulo.

[...] cada indivíduo, seja homem ou mulher, possui uma visão (observação) diferente (para um determinado objeto em análise), sendo que esta observação é baseada nos conhecimentos que cada um adquiri ao longo de estudo.

Já no seguinte exemplo, embora o foco permaneça em quem observa, a natureza da observação estaria associada a características que seriam pessoais,

2. Não foram realizadas correções ortográficas nas interpretações transcritas. 
como racionalidade e emotividade:

As pessoas têm diferentes modos de analisar e interpretar os dados e fatos observados. Alguns observam mais racionalmente, outros mais emocionalmente. Por isso há diferentes interpretações do mesmo fato.

\section{Contribuições para a formação docente}

Relatos sobre como estão sendo desenvolvidas as aulas de física no ensino básico na maioria das escolas no Brasil apontam para as chamadas aulas expositivas com o professor solucionando exercícios na maioria do seu tempo em classe. Essa situação se coloca em oposição às estratégias e recomendações que explicita ou implicitamente podem ser inferidas da grande quantidade de investigações desenvolvidas na área de educação em ciências. Sabemos, por outro lado, que disciplinas dos currículos de licenciaturas das áreas de ciências têm incorporado grande parte dessas investigações como conteúdos a serem desenvolvidos na formação inicial dos professores.

É fato, entretanto, que esses conteúdos, associados aos conhecimentos produzidos na educação em ciências, podem ser trabalhados com diferentes estratégias. Se, por exemplo, aos licenciandos forem apresentados apenas os resultados das investigações como indicadores da maneira como eles deverão trabalhar quando forem professores, não é difícil imaginar que esses indicadores possam se constituir no que Almeida (2006) chama de recomendação vazia. O que, segundo a autora, ocorre quando são fornecidos resultados satisfatórios decorrentes de determinados procedimentos de ensino, sem que estes sejam acompanhados dos fundamentos e das condições em que foram gerados os procedimentos sugeridos.

Não descartamos aqui a relevância para a formação do futuro docente deste se inteirar de trabalhos anteriormente realizados, desde que estes possam ser compreendidos no conjunto de suas partes constituintes do objetivo aos resultados e à sua discussão, incluindo as condições em que o estudo foi realizado e o referencial teórico em que os autores se basearam. No entanto, consideramos que atividades, como as que descrevemos neste estudo, ultrapassam a aquisição de conhecimentos, tendo alto potencial de gerar a reflexão.

Por possibilitarem o trabalho em classe com interpretações produzidas nas 
condições organizadas pelo professor e subentenderem aspectos das memórias discursivas dos licenciandos, elas são manifestações de seus imaginários, que podem ser debatidas em classe com a participação deles próprios e do professor. Às mediações que foram ocorrendo em diferentes momentos da atividade, devidas ao funcionamento direcionado dos recursos utilizados, podem, no debate, se somar mediações orientadas pelo conhecimento que o professor passa a ter das interpretações dos estudantes e, inclusive, pelo que a opinião dos colegas acrescenta à reflexão de cada um.

\section{REFERÊNCIAS}

ALMEIDA, M. J. P. M. Discursos da Ciência e da Escola: ideologia e leituras possíveis. Campinas: Mercado de Letras, 2004. 127p. . Prescrições e recomendações ao professor na solução de problemas do ensino na Educação em Ciências. Ciência \& Ensino, v. 1, n. 1, p. 47-51, dez. 2006.

BRASIL. Parâmetros Curriculares Nacionais do Ensino Médio: ciências da natureza, matemática e suas tecnologias. Brasília: Ministério da Educação e do Desporto, 1999.

CHALMERS, A. F. O que é Ciência afinal? São Paulo: Brasiliense, 1993.

DOURADO, L.; SEQUEIRA, M. Uma análise da relação entre os conceitos de método científico e de investigação. Disponível em: <http://webpages.ull.es/users/ apice/pdf/351-076.pdf $>$. Acesso em: 05/12/2007.

HANSON, N. R. Observação e interpretação. In: MORGENBESSER, S. Filosofia da Ciência. São Paulo: Cultrix, 1975. p. 127-138.

LÉVY-LEBLOND, J. M. É possível ensinar a física moderna? In: MORIN, E. (Org.). A religação dos saberes: o desafio do século XXI. Rio de Janeiro: Editora Bertrand Brasil Ltda., 2002. p. 69-72.

MILLAR, R. A means to an end: The role of processes in science education. In: WOOLNOUGH, B. (Ed.). Practical science. Milton Keynes: Open University, 1991. p. 44-52.

MORIN, E. (Org.). A religação dos saberes: o desafio do século XXI. Rio de Janeiro: Editora Bertrand Brasil Ltda., 2002. p. 27-72. 
ORLANDI, E. P. Discurso \& Leitura. Campinas: Cortez Editora/Editora da Unicamp, 1988.

. Interpretação: autoria, leitura e efeitos do trabalho simbólico. Petrópolis-RJ: Vozes, 1996.

SILVA, F. D. A. Método científico e prática docente: as representações sociais de professores de Ciências do Ensino Fundamental. 177f. Mestrado (Pós-Graduação em Educação) - Universidade Federal de Uberlândia, Uberlândia, 2007.

SILVEIRA, F. L. A filosofia da Ciência e o Ensino de Ciências. Em Aberto, n. 55, p. 36-39, 1992. 